\title{
A Significant Connection of an Organization's Information Ecology for Knowledge Management and Developments
}

\author{
Chammika Mallawaarachchi and Zhang Xiangxin
}

\begin{abstract}
-this paper hopes to persuade readers of any organizational setting on how to become accustomed to the information ecology to survive in knowledge competitive atmosphere. For that, based on literature review, the main elements of the information ecology, information politics, information culture and information technology, how bring prosperity for an organization is discussed. The results shown that many organizations have been ignoring ecosystem of the organization thus unable to find potentials for vital sustain of the organization. Therefore, in details why information ecology of the organization is very important and how it uses for the organizational development is discussed both in theoretical and practical ways.
\end{abstract}

Index Terms-: Information Ecology, Information Culture, Information Politics, Knowledge Management

\section{INTRODUCTION}

Ecology is a science use to analyze the relationship between members or species of a community and their interaction with the environment. Ecological study has been conducted at the species, the population, the community, and the ecosystem level. Species are the basic element in ecology. A group of organisms of the same species occupying a particular space at a particular time form a population. Several populations gather together to become a community. The community forms a specialized network and becomes an ecosystem. For example, a Staff Development Centre of a university is one of a specialized network. In this network all elements, knowledge, resources, environment and technology, have equal values. Ill function of one element directly effects to the entire information ecology. Thus, unable to identify the organization's information ecology may lead to collapse or unsteady development processes.

Given the scenario, this paper discusses ways in which to identify an organizational barriers such as information politics, information culture and information technology to its success. For that without given priority for any especial organizational settings, the paper discusses in general how to use the concept of information ecology to promote an organization's knowledge to its.

Arrangement of the paper is basically in three sections. First section discusses what knowledge and knowledge management is. In section two discusses what information ecology is and its other components that are information politics, information culture and information technology ways in which to identify obstacles in an organization. The last section sums up the main ideas of the paper and while discussing challenges may be faced at the implementation process of an organization.

\section{KNOWLEDGE AND KNOWLEDGE MANAGEMENT}

Knowledge is capacity to act. As Peter Drucker notes knowledge is information that changes something or somebody either by becoming grounds for actions, or by making an individual (or an institution) capable of different or more effective action. So, knowledge acts an ecosystem and it indicates how its species work together to create new knowledge. To shape the knowledge it has to be communicated effectively and efficiently at all the species of the knowledge ecosystem. Therefore, knowledge is not an individual component of the ecosystem, but it is a series of process: from data to information; intelligence to wisdom; wisdom to knowledge and then form entire information ecology. Thus, a way of forming new knowledge can be shown in figure 1 as following.

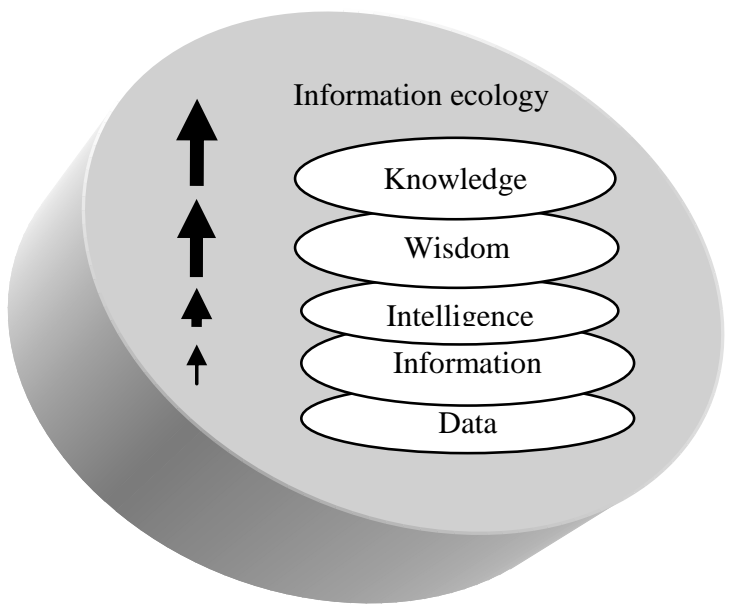

Fig. 1. Outline of knowledge in Information Ecology Perspective

Statistics on population is data sets. Source sets, databases, help desks, are repositories of information. Use intelligence to create or form new knowledge based on collected data and information. In addition, data and information are not knowledge because they do not have capacity to act. Also, knowledge cannot be managed. For example, a testing taste of wine is knowledge. To use that knowledge requires a certain level of intelligence. However, having wisdom, knowledge can use through collaborative intelligence. Wisdom is an effective use of intelligence and then it tells what to pay attention to and what to communicate. In general view it is so-called knowledge management.

Knowledge management is used to describe the 
management of information based knowledge assets within an organization. There are many definitions of knowledge management. Duffy (2000) defines knowledge management as a discipline that encourages a mutually supported method to create, capture, arrange and use information. While, the nature of knowledge Schultze and Leidner (2002) describe as metaphors and knowledge views as an object, an asset, and as situated practice. These differentiations are based on how knowledge ope-rationalized.

Polanyi (1966), Nonaka and Takeuchi (1995) differentiate knowledge into explicit and tacit knowledge. Explicit knowledge is factual knowledge that can be easily transferred like in documents. Tacit knowledge is intuitive knowledge that is generally gained through personal experience, like "crafting a violin, or interpreting a complex seismic printout of an oil reservoir".

Recently the concept of community of practice becomes a one way of knowledge management. Community of practice is a place that in acculturation, fascination, and real learning take place. Wenger and Synder (2000) note community of practice by nature organic, unstructured, informal and ecological while it has been emerging as a very effective tool to communicate among many organizations today.

An ecological approach to knowledge management was introduced by Davenport and Prusak in 1997 with a concept of information ecology. They focus on humans centered information management model in the information environment, the organizational environment that surrounds it and the external environment of the marketplace. The complete information environment addresses all of the firms values and believes about information (culture), how people actually use information and what they do with it (behavior and work processes), the fit falls that can interfere with information sharing (politics), and what information systems are already in place (technology).

However, the Community Intelligence Lab (2000) urges that the ecology metaphor has been previously used to describe the use of knowledge within organizations. In particular, the term knowledge ecology has been used to illustrate how ideas are exchanged, innovation blossom, values is add to information, and new knowledge is tested and applied through accrued expertise and learning and within the rich perspective of the ecosystem. Therefore, information ecology, in general, is different form knowledge management. Information ecology, in particular, does not claim to institutionalize new ideas nor knowledge itself be managed. It is seen as an organic and evolving solution that exists over time. Information ecology has been used as a framework to show how the goals and objectives of an organization can be cultivated of that the individual. The ecological framework expands on traditional concepts of knowledge management and a wide range of disciplines such as organizational learning (Senge 1997) to intellectual capital (Sveiby 1997) to information ecology (Davenport and Prusak 1997) to communities of practice (Brown 1999; Wenger and Snyder 2000). An ecological framework, however, moves beyond the learning community to engage outside forces and influences beyond its own boundaries and expertise for inspiration, challenge and validation. As Brown (2000) emphasis knowledge [information] ecology stretches beyond communities of practice to include an external environment that is dissimilar from itself, which add an intrinsic dimension to the knowledge and learning that occurs within the community as a whole.

\section{INFORMATION ECOLOGY}

The concept of information ecology, the complete information environment, was introduced by Davenport and Prusak in 1997. The basic concept is that the information ecology is an organization's information environment and consists of numerous interacting and interdependence social, cultural and political sub-systems that shape the creation, flows and use of information in the organization. Thus, the organization's information ecology influences what information is produced, and stored, what information is made available and to whom, and what information is required and valued in task performance. For example, advocacy forum on human smuggling is hidden information ecology within a group of experts on advocacy.

However, the framework of information ecology attempts to emphasize people rather than on the hardware, software or telecommunication networks. According to Davenport and Prusak [1] the key premise of the information ecology is organizations need to focus beyond the "machine engineering" but focus on the technologies of information. And then here, the complete information environment addresses all of the organization values and believes about information (culture); how people actually use information and what they do with it (behavior and work processes); the fit falls that can interferes with information sharing (politics); and what information systems are already in place (technology in finally).

The proponents of the information ecology, in fact, have criticized the simplistic assumptions of the information processing model of organizational information systems. However, instead of a sole on technology, the information ecology puts how people create, distribute, understand and use information. It is understood that in the information ecology the humans are very important than any other elements of an organization. It means so-called technology. Therefore, based on the model of information ecology, we can identify key components of the organization's information ecology that are: information politics, information culture and information technology. So, information politics involves the power of information providers and the governance responsibilities for its management and use. Information culture comprises an organization's information behaviors and information use. However, in fact, information behaviors include encouragement of information sharing among organizations while addressing various political, emotional, and technological barriers. And then information use determines that how valuable information shares across the organizational boundaries, disclose internally and externally, and capitalize on it in their businesses. And finally information technology is already existing information 
applications/systems of the organization.

\section{A. Information Politics}

An indescribable notion of an organization is the information politics. Travica [2], Davenport et al. [3] define the information politics in terms of power, agendas, and fights or flights that are related to organizational information and information technology. Many occasions it has shown that information politics constitutes high political stakes. For example, if one staff member has special knowledge that others can consider as a resource, the knowledge holder can influence thought and behavior of others.

However, we as information seekers and beneficiaries of it, assume that information and communication technologies suppose to stimulate information flow and eliminate hierarchy, but that was not. Given the situation, Devonport et al. [3] identify five models of information politics and urged many organizations are likely to have proponents for more than one of the identified models of information politics.

A model of technocratic utopianism is a technical approach to information management that on stressing categorization and modeling of information assets heavily on emerging technologies. For example, the Internet marketing world the technology savvy marketers towards on this model on sharing of knowledge/information on products and services. Absence of having information management policy while leaving individual to obtain and manage their own information is indicating practicing of anarchy model of the information politics. This may lead someone to urge that having a neutral information politics in an organization, however it is not a real practice. Think of some online forums how they hold to not to share information/knowledge without getting required details of the information seekers. This may lead to another model of the information politics that is feudalism. An individual [person/unit] defines their information needs and report only limited information/knowledge to the overall corporation. However, define of information categories and reporting structures by the firm's leaders, who may or may not share the information willingly after collecting is another model of the information ecology that is called as monarchy. But, federalism information politics model is approaching to information management base on consensus and negotiations on the organization's key information elements and reporting structures.

However, in fact looking into information politics of many organizations that indicate they are not hold only one model of information politics instead of having two or more. And some occasions holding interactions among many so it is unable to predict which information politics model/s is holding. However, it is very clear that many organizations in the world are holding one of following information politics models in their organizations where information ecology of the organization is concerned. Following figure two depicts models of information politics in information ecology view.

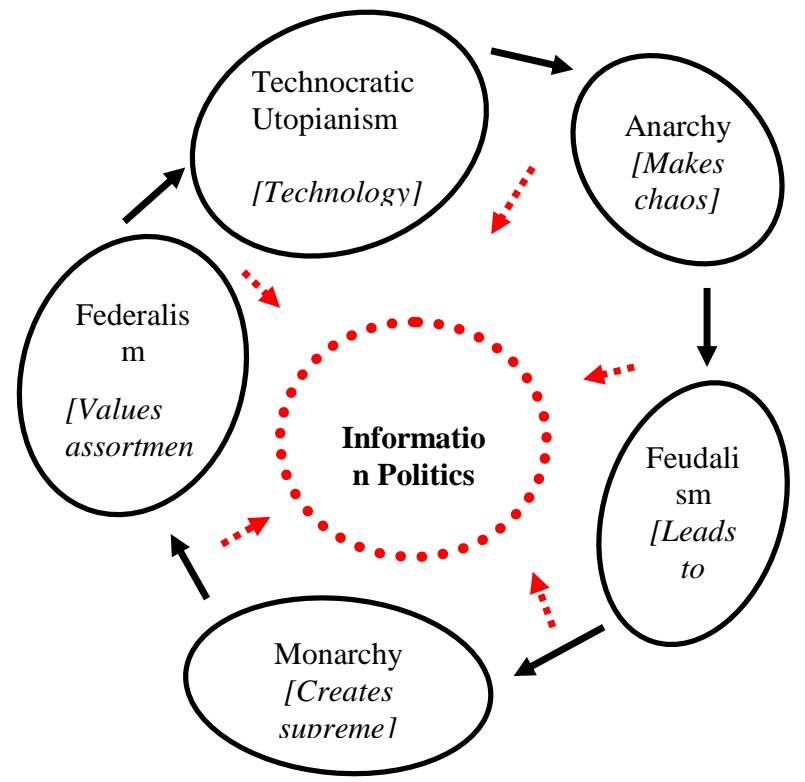

Fig. 2. Models of information politics in Information Ecology perspective

It shows that technocratic utopianism ignores politics, anarchy is politics run amok, feudalism involves destructive politics, monarchy attempts to eliminate politics through a strong central authority and federalism treats politics as a necessary and legitimate activity by which people with different interest workout between themselves a collective purpose and means for aching it.

However, an organization is more focusing on developments while using an appropriate information politics models as required, it is advisable that better to consider which model is people of the organization is currently holding, pre-dominating, pleasing, and ways in which achieving it. Therefore, it seems to be that a model of federalism is a good practical choice to enhance information ecology of an organization to collectively going for developments. Business culture we live today is very participative therefore for any organization the information politics models of federalism is preferable; however it is harder to achieving. But, continually working towards to achieve it the results are obvious.

\section{B. Information Culture}

An organization culture is being coinciding that is a very good starting point to discuss the information culture of an organization. Information culture and organization culture cannot be discussed separately, in particular, both are focusing on its values, assumptions and beliefs therefore all are common attributes. How important the human attribute for the information culture and organization culture is discussed by Peppard and Ward [4] and urge requiring inspired management and leadership the people within the organization will be a major cause. With that, Davenport and Prusak [1] define information culture in terms of a pattern of behaviors and attitudes that express the organization's orientation towards on information. For example, information cultural attitudes are preferences for facts or rumors where as behaviors include information sharing and preferences for types of communication channels. As we know at present 
many organizations value creation assets are human resources. That is based on explicit and implicit knowledge. As Davenport et al. [5] define knowledge as information combined with experience, context, interpretation and reflection; therefore the knowledge management process must give equal attention to knowledge storage, distribution and integration to achieve significant organizational developments. For that an organization culture and the information culture is very important.

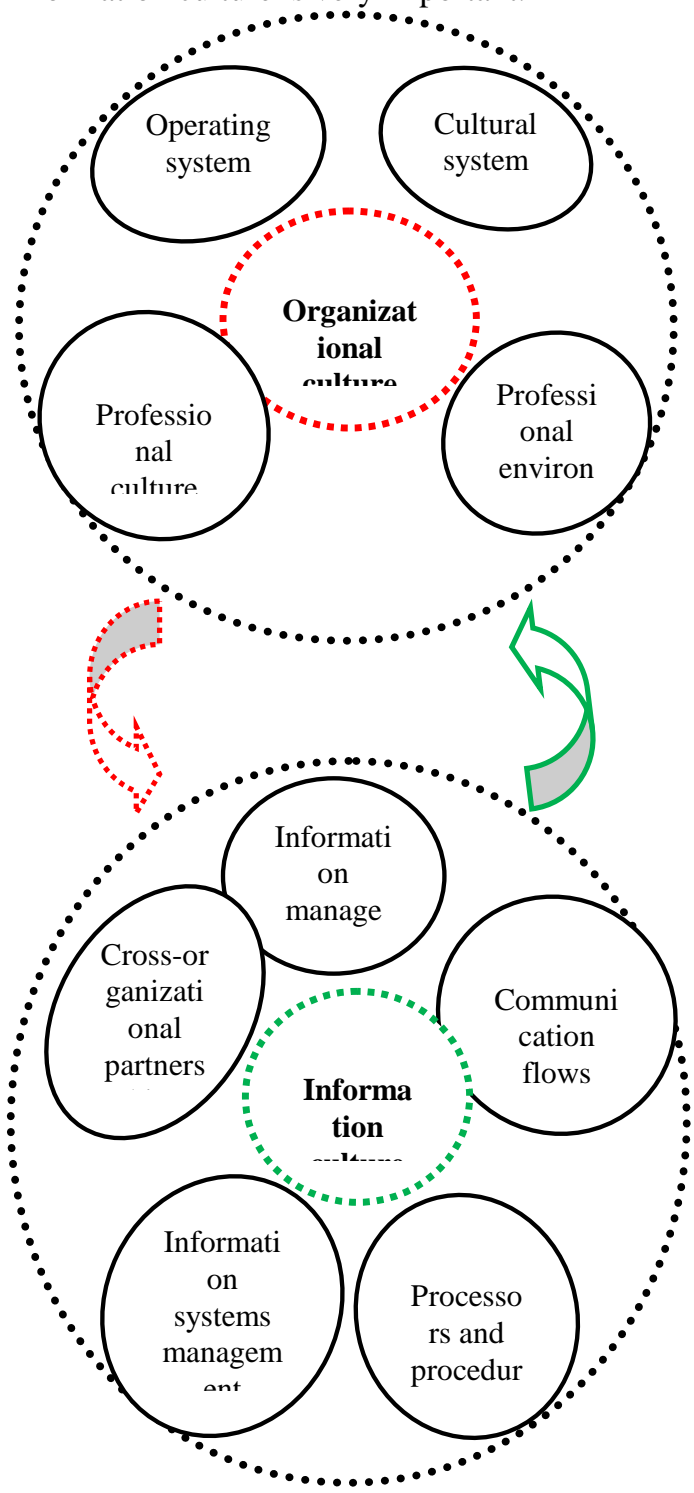

Fig. 3. Information culture of an organization in information ecology perspective

With these mixtures of the information culture and organization cultures appear to be an integral process of knowledge organization while fulfilling the requirements for information culture and encourage an organizational culture towards learning. Thus, an organization is first better to adapt to the information culture then communicates the ethos and demonstrates commitment by re-structuring to reflect the components of information culture. At this stage information culture is no longer distinguishable from the organizational culture and the organization has evolved into one in which the availability and use of information is inherent in everyday activities. To build healthy information culture key elements that are participants, processes and information are vital while integration of the information culture and organization culture. While, Bloor and Dawson [6] model indicate dynamic interactions: operating and cultural systems, historic and social contexts, external organization context and professional culture and then the environment. However, it is very clear that to develop a proactive the information culture in an organization five elements of the organization culture assists and lead for that. A figure two is depicting a combination relationship of the information culture and organization culture how to evolve for organizational developments.

The operating system, human and technology, is organizational infrastructure. Shared values and beliefs of the people in the organization is cultural system. For cultural system of the organization is two ways. A vision of organization, values, infrastructures, influences are referring to the historic context of the cultural system of the organization. Expectations, norms and values of the society are social context of the organization culture. However, in fact not only operating system and cultural system is influencing to organizational culture, but also the external organizational environment. Therefore, to the organization culture, the professional culture and its sub-cultures are largely influencing factors. To form healthy information culture of an organization, its organizational culture is being directly influencing. To form healthy information culture processors and procedures on information/knowledge will lead to successful information management and information management systems. If these systems are up and running very smoothly, then its communication flows run in good manner, then building of cross-organizational partnerships and strengthen of good information culture at all levels of the organization easy and may have not arisen misunderstanding or miscommunications within and among units or organizations at large scale.

Hence, for healthy information culture the elements of structural, communication, social and psychological, is very much important. Those will assist to create and share knowledge widely. For example, organizational structures, hierarchies, functional differentiation and separation cause to building of healthy information culture at the organization. At the same time, communication structures either horizontal or vertical, and communication channels are important factors. Therefore, unrestricted flow of information/knowledge in the organization is very much concerned in information ecology because knowledge diffusion not only requires the spatial distribution of knowledge, but also the readiness to share and to pick up knowledge important for in social physiological aspects of the organization's information culture.

\section{Information Technology}

Information technology is a very broader to the concept of information ecology. An existing information technology is only one segment of an organization and there are very active and vast domains of information technology outside the organization. Knowing this the information ecology urges that technology is an only one component of the information environment and often not the right way to make organizational changes. Therefore, in fact, it worth knowing users of information technology, comprehend the maximum 
benefits. At the same time, it is vital to understand how people interpret, perceive and act on information. As you know people are at the center of the information ecology and any change in the ecology will affect them than other sub-systems of the organizational ecosystem. Hence, people have a profound influence on the functioning of all other inanimate elements in the information ecology. The perceptions of organizational structures and roles by people have a marked impact on the way the organizational functions. Thus, changes in the information ecology must be planned in such a way that the perception of all stakeholders affects the performance of the system positively.

However, a rapid development of information technology is a big challenge for the organization knowledge distribution and management process because if the existing systems are not flexible enough to evolve in response to the opportunities and the requirements of the external environment. For example, often the organization strategists focus on the internal structure of the organization to match the requirements of the market. To respond quickly to the change in market conditions, a flexible and evolving internal structure is required. Hence, a static and inflexible information systems will not help the organization sustains and it will become a stumbling block in the way of organizational excellence by limiting the potential growth.

So given the situation, the information ecology describes the convergence of several disparate, but linked technologies such as instructional designs, multimedia technologies, computers and telecommunications technologies, content area expertise, and business and industry linkages. In fact, that is the interaction of the systems in the overall organization ecology, rather than depict information systems on technical architecture and engineering drawings. Therefore, this is more suitable for information engineering than the conventional methods of system architecture because it is better to understand social events both in market and technology perspectives.

\section{CONCLUSIONS}

This study shows that in knowledge competitive advantages, existing concepts on knowledge management has been drastically changing. Knowledge is growing organism and cannot be managed. Therefore, information ecology, knowledge, communities, organizational resources and external environment, has potentials to encounter greatest challenges in knowledge creation, distribution, transfer, diffusion and management where an organizational development is concerned. Of that, study discusses the important components of the information ecology: information politics; information culture; and information technologies ever-changing the social and technological phenomena in particular in the information ecological perspective. The information politics is one barrier of information leveraging and its affect to the overall information function of the organization. Positive the information culture can cultivates knowledge sharing habits while it integrating the organization culture and also it helps create a sustainable organization. And information technology is not only hardware and software, but also including other technological elements to keep smooth functions of the organization.

However, to implement information ecology in organizational developments may face basically three challengers: human, social and institutional, and technological.

Humans influence is the biggest challenge because working with emotional responses to artificial knowledge agents obviously will become conflicts. Historically, knowledge and intelligence have been the distinguishing characteristic of human beings. Now computers are able to take over some of the routine and even the expert functions of knowledge work. In some areas computers' excel over humans capabilities. A related problem is the very natural humans' fear that computerized the information ecology come dangerously close to replacing humans in knowledge work. This conflict is an intensely emotional matter. Like other emotional issues it remains largely suppressed in organizations.

The next challenge is to face the organization's the social and the institutional environments. This stage carrying out of the information ecology is more challenging and more conflicts than humans' level. In this stage, it affects to the whole organization's functions, tasks, and performance. At the same time, it changes career prospects and earning potential of members. The organizational members require retraining due to changes in structures and systems, and also installation of new equipment.

Above problems compound by the lack of comprehension of what the information ecology represent. In some senses, the information ecology is an extended virtual brain of the organization. Knowledge functions and access of this ecology extends well beyond the cognitive capacity for individual humans or even departments and divisions. It represents a new form of organized complexity that many managers and workers find incomprehensible. It falls outside the collective cognitive map of the organization.

\section{REFERENCES}

[1] Bloor. G., Dawson. P. Understanding Professional Culture in the Organizational Context. Journal of Organisation Studies 15(2). 1994 p. 275-295

[2] Brown, J.S. Sustain the ecology of knowledge. leader to leader, 12, 1999,pp 31-36

[3] Boisot. M. "Information and Organisations: The Manager as Anthropologist. Fontana/Collins:London. 1987.

[4] Davenport. T.H, Prusak. L. "Information Ecology: Mastering the Information and Knowledge Environments”, Oxford University Press: New York. 1997.

[5] Davenport. T.H., Eccles. Robert G., Prusak. L. Leadership and Organizational Studies, Management of Technology and Innovation Information Politics. Sloan Management Review, Fall 1992, pp. 53-65

[6] Davenport. T. H., De Long. D. W., Beers. M. C. Successful Knowledge Management Projects. Sloan Management Review, 39(2). 1998, pp. 43-57

[7] Duffy, J. Knowledge Management: To be or not to be? Information Management Journal, 34(1), 2000, pp 64-67

[8] Nonaka. Ikujiro, Hirotaka. Takeuchi "The Knowledge-Creating Company: How Japanese Companies Create the Dynamics of Innovation, Oxford University Press: New York. 1995.

[9] Polanyi. M. "The Tacit Dimension". Garden City:New York. 1966. 
[10] Peppard. J, Ward. J. "Mind the gap: Diagnosing the Relationship between the IT, Organization and the Rest of the Business". Journal of Strategic Information Systems, 8. 1999.

[11] Schultze. U, Leidner. D. E. "Studying Knowledge Management in Information Systems Research: Discourse and Theoretical Assumptions". MIS Quarterly Vol 26(3). 2002, pp. 213-242

[12] Senge, P.M. Communities of Leaders and Learners, Harvard Business Review, 75(5),1997,pp. 30-32

[13] Sveiby, K.E. The New Organizational Wealth: Managing and Measuring Knowledge based Assets, San Francisco, Berrett-Koehler, 1997, pp.29-37

[14] Travica. Bob. "Information Politics and Information Culture". home.cc.umanitoba.ca/ btravica/vita.html, 2010.

[15] The Community Intelligence Lab - www.co-i-1.com

[16] Wenger, E.C and Snyder, W.M. Communities of Practice: an Organizational Frontier, Harvard Business Review, 78(1) 2000 pp.139-145
Chammika Mallawaarachchi is born in 1973 in Colombo in Sri Lanka. He has completed his Honers Degree in Library and Information Scinece, University of Kelaniya, Sri Lanka, in 2000. Earned Master degree in Managemet Science, at Jilin University, P.R China, in 2010. Now he is a $\mathrm{PhD}$ scholar in same university and reading Information Science.

$\mathrm{He}$ was a teacher and a Project Manager. Now he is a fulltime academic staff member of University of the Visual and Performing Arts in Sri Lanka. He has published many articles and most recent publications are: human centered knowledge paradigm for building a secure and prolong society: the knowledge ecology perspective; Content marketing is an interactive way of reaching out a technology savvy and the Internet era customers; and an organization's knowledge identification and knowledge promotion is a way to harness information: knowledge ecology perspective: a literature survey.

His research intresting area is knowledge management in perticular Information Ecology and Knowledge Ecology perspectives.

Zhang Xiangxin is born in P R China and now professor at School of Management in Jilin University in Changchun, China. 